\title{
An Approach to the Worth-Living Integrated Development of Small Isolated Greek Islands: The Case of Agios Efstratios Isl., Northern Aegean
}

\author{
Athanasios Tatsis \\ Interdisciplinary Program of Postgraduate Studies (IPPS) \\ "Environment and Development" of the National Technical \\ University of Athens (NTUA), Greece \\ than.tatsis@gmail.com
}

\section{Elya Michailidou}

Metsovion Interdisciplinary Research Center (MIRC)

Interdisciplinary Program of Postgraduate Studies (IPPS)

"Environment and Development" of the NTUA

National Technical University of Athens (NTUA), Greece

elmich@central.ntua.gr

\author{
Angeliki Geronteli \\ Metsovion Interdisciplinary Research Center (MIRC) \\ Interdisciplinary Program of Postgraduate Studies (IPPS) \\ "Environment and Development" of the NTUA \\ National Technical University of Athens (NTUA), Greece \\ ageron@central.ntua.gr
}

Publication Information:

Received 4 February 2020, Accepted 14 March 2020, Available online 29 June 2020

DOI: $10.21463 /$ jmic.2020.09.1.04

\section{Abstract}

Small remote islands of Greece are mainly characterized by geographical isolation, minimal utilization of their resources, limited economic activities and population shrinkage. Restrictions and problems that negatively affect their attractiveness and make it necessary to implement actions, not only to prevent visible threat of future abandonment but also to attract new people for permanent living. In an attempt to redefine the development framework for islands with these characteristics, a new approach is proposed, based on the interdisciplinary seven steps methodology to the worthliving integrated development. This approach, unlike today's policies, focuses on the particular elements of the island's physical and socioeconomic reality, as well as their interdependences, interactions and changes over time for utilization of all possible perspectives. This methodology is applied to Agios Efstratios Island in Aegean Archipelago where, on the basis of on-site research and consultation with the local community, their vision is revealed, active participation and 
cooperation is requested and fifty actions are defined in political, social, economic, cultural, technical-technological dimension and the environment, natural and man-made, for the implementation of a holistic development plan in order to create worth living conditions on Agios Efstratios, for the islanders themselves and beyond.

\section{Keywords}

Agios Efstratios (Ai Stratis) Island, Worth-Living Integrated Development, Insularity, Isolated Islands, Participatory Planning

\section{Introduction}

The moral base of island policy is based on the most fundamental element of comparative justice, which is usually attributed to the Greek philosopher Aristotle: "Treat equals equally and un-equals unequally in proportion to their differences", which means that it is a violation of the principle of equality to treat those who are not equal in the same way. According to the European Court of Justice, discrimination consists in treating differently situations which are identical, or treating in the same way situations which are different (EUR-Lex, Cases T-6/92 and T-52/92, 1993; Case $08 / 82,1983)$. Hence, it is a clear discrimination against the islands to apply same policies and rules to areas with different characteristics, when these characteristics are permanent, natural and can't be changed.

The island characteristics that are considered permanent and constitute elements of 'insularity' are the small size and geographic discontinuity that inevitably lead to limited productive resources, social isolation, population - demographic problems, restrictions on infrastructure and transport networks, dependence on seasonality, small product market and limited economic activities (ESPON, 2013, p.36). Insularity appears to be proportional to the geographical discontinuity of space and distance from the mainland, while it is inversely proportional to the size of the islands (Koutsopoulou, 2013). The effects of insularity are exacerbated in the case of Archipelagoes, like the Aegean, since fragmentation of the domestic market exacerbates the constraints facing the islands, thereby causing the so-called 'double insularity' (Deidda, 2016). Furthermore, islands are characterized by vulnerability and fragility, considering all aspects of their environment which, undoubtedly, consist inhibiting factors to developing processes (Tsoukala et al, 2018).

Although, the need for a different development approach to islands, especially the small isolated ones, has been recognized internationally, Greece has little progress in this direction (Koutsopoulou, 2013). This is due to the fact that national development planning is essentially a transfer of European guidelines for the whole country. The National Strategic Reference Framework (NSRF) 2014 - 2020, the Regional Operational Programs and the Sectoral Programs, formulate European policy goals, proposing actions and measures, in order to achieve the same competition conditions between metropolitan and island regions of Greece as part of a single market strategy. This process is not only a 'top down' approach to the governance of Greece, but a model of policy and design from 'outside to inside' and then 'top down', ignoring the important problematic parameters concerning the island space (Alatzas et al., 2016, p.785). Insularity of Greece and the small size of the majority of the islands make it necessary to investigate the inhibiting development factors in order to formulate a strategic model of integrated development for the insular space (Koutsopoulou, 2013). 
Additionally, the usefulness of composite sustainability indicators as tools to measure sustainable development and shape policies seems very limited (Karampela et al, 2017). These development indicators fail to capture the living level of local communities and are unable to reveal inequalities and qualitative variations (Udo and Jansson, 2009). Similarly, the development plans and programs designed and based on these indicators, ignore the specific circumstances and peculiarities of the natural and socio-economic reality of each area / region, as well as the desires and needs of the inhabitants. The substantial differences of every region and their communities make it necessary to study the specificities of each area for planning an effective and integrated development strategy (Koroneos and Rokos, 2012).

\section{The Seven Steps for the Worth-Living Integrated Development}

The peculiarity of this research lies in the implementation of the interdisciplinary methodology and analytical critical approach of the seven steps to the Worth-Living Integrated Development (Koroneos \& Rokos, 2012; Rokos, 2004). This methodology focuses on halting the one-dimensional and fragmentary approach of development and environmental planning, utilizing the particular features of the study area for the best possible and effective development plan (Rokos, 2007). The ultimate goal is a genuinely interdisciplinary partnership that goes beyond the boundaries of scientific fields and, through consultation and critical consideration, will result in integrated proposals to address essential issues, such as nutrition and water self-sufficiency, poverty alleviation, energy efficiency, biodiversity conservation, climate change impacts, etc. (Leemans, 2012). The implementation of this framework to regions with particular geographic and social characteristics which have not been extensively studied so far, like the small isolated islands of Greece, could effectively fill the gaps of one-dimensional policies that widely apply to the island regions of Greece. Moreover, in an effort to highlight 'islandness' problems, the present study attempts to address the real living conditions of locals, beyond statistics.

In this way, according to Rokos $(2003,2007)$, the methodology of the worth-living Integrated Development of a region was shaped as:

"the appropriate economic, social, political, cultural and technical/technological development, simultaneously in space and time, that is always pursued in dialectical harmony and with respect toward human beings and their natural and cultural environment, in which they behave and act peacefully and creatively, as an integral part and not as owners, dominators and exploiters".

This holistic and interdisciplinary seven step methodology was formulated as below:

1. Interdisciplinary and holistic documentation, agreement and acceptance from the bodies relevant to integrated development initiatives, which principles, values, goals, actions and practice, are seen as an optimum choice,

2. Conducting the necessary research and studies of Integrated Surveys of the natural and socioeconomic reality of each area/ region (as well as the multidimensional relationships, interdependences and interactions) and systematic monitoring of their changes through time,

3. Analysis of the data that constitute the natural and socioeconomic reality of the area (historical, statistical, bibliographical, climatic, using results from properly structured questionnaires, records, views and proposals of habitats and bodies of the area, remote sensing data, data from specific research and studies etc.),

4. Formulation and documentation of alternative scenarios for the integrated development of the area/region, 
5. Investigation of the problems, the implementation potentials and the objective restrictions of each scenario,

6. Pre-assessment and evaluation of the balance between positive and negative elements of each scenario and choice of the optimum scenario for the Integrated Development of the area/ region.

7. Implementation of the optimum Integrated Development scenario for the area/ region, constant monitoring of actions and their progress, reporting and feedback.

However, for the purposes of this paper, due to the absence of sufficient interdisciplinarity, steps (4), (5) and (6) of the above methodology were merged into one. The proposed actions were adjusted to the geographical scale of Agios Efstratios Island and derived from consultation and interaction with the local community, in an effort to enhance the islanders to speak with voice, as they were "their own consultants, rather than the consulted" (Pugh, 2013).

\section{Agios Efstratios Island, Necessity for a Different Development Framework}

Agios Efstratios is an isolated island of the northern Aegean Archipelago which covers a small geographic area, approximately $49.6 \mathrm{~km} 2$, with a single settlement and population of 270 inhabitants. The Municipality of Agios Efstratios belongs to the Peripheral Module of Lemnos of the North Aegean Region (Strategic and Operational Program of Agios Efstratios Municipality 2015-2019, 2015 p.5, 6). Its geographic isolation and the character of an inaccessible place were the cause of being known in the past as a place of displacement for political prisoners in Greece (Democracy Museum, 2020).
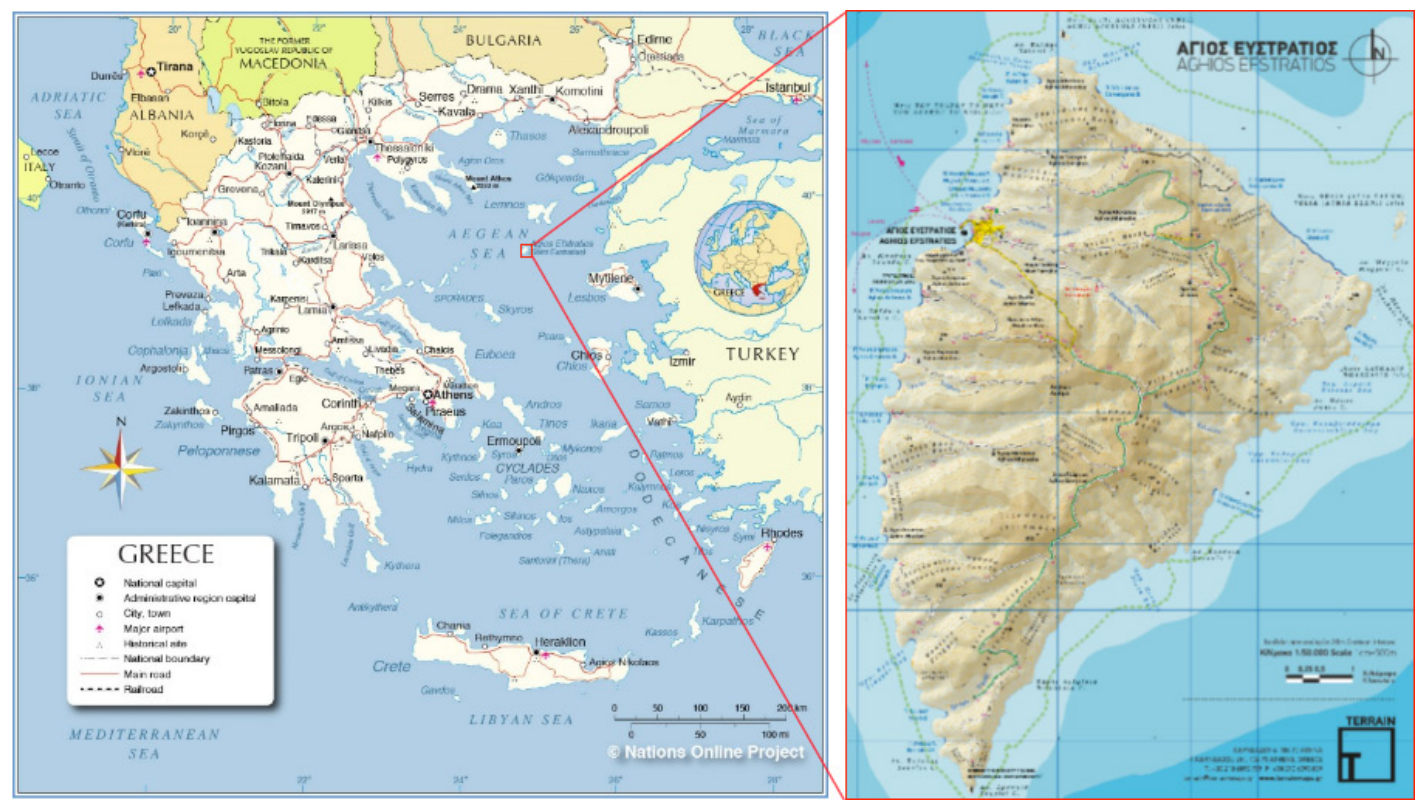

Fig 1. Political Map of Greece \& Map of Agios Efstratios Island. Sources: The Nations online Project, 2019 \& TERRAIN maps, 2009. 
The island of Agios Efstratios is characterized by serious development problems, such as population reduction, severe infrastructure deficiencies and a minimal utilization of its resources (quantitative and qualitative) (Strategic and Operational Program of Agios Efstratios Municipality 2015-2019, 2015) that have intensified during the multidimensional crisis in Greece. The country is shrinking rapidly, forecasting a population reduction of $14.5 \%$ by 2050 (Linardaki, 2016) and, according to Eurostat estimates, Greece will not exceed 7.2 million inhabitants in 2080 (Emke - Poulopoulou, 2018). Small islands are abandoned by their inhabitants, as a result of longstanding indifference and misguided policy, undermining a national danger with unpredictable consequences (Stavropoulos, 2015).

In the recent history of Agios Efstratios Island, two events have largely determined today's reality (Tatsis, 2016). First, it was the place with the longest displacement period for political prisoners in Greece during the 20th century, acquiring the unfortunate 'distinction' of referring to an island for the 'punished' people [Ai Stratis. Photographic Traces (19401970), 1999 p.194]. The second event was the strong 7,1M earthquake of 1968 (Pavlides \& Tranos, 1991) and the subsequent interventions by the ruling Dictatorial Regime with many negative impacts that exacerbated the abandonment of the island by its inhabitants [Ai Stratis. Photographic Traces (1940-1970), 1999, p. 213; Lalenis, 2010, p. 177]. These facts have negative impact, even nowadays, on its attractiveness, a really important factor to halt population shrinkage and attract new people for permanent residence (Spilanis et al, 2003).

Until now, no European or National Development Strategy has taken under consideration the particularities of Agios Efstratios, in order to effectively deal with the consequences of the earthquake and the interventions of the Dictatorship in the social formation, cultural identity, life and psyche of Agios Efstratios people, inhabitants and emigrants (Giannos, 1983, p. 118; Ai Stratis. Photographic Traces (1940-1970), 1999, pp. 213-217). These specificities were noticed during the field search, through the testimonies of the locals. The reformation of Agios Efstratios has been recognized by the Government as a national obligation (Lalenis, 2010, p. 179). However, the applicable policies do not have the desired effects on this isolated island of Greece, despite the efforts of the local authorities.

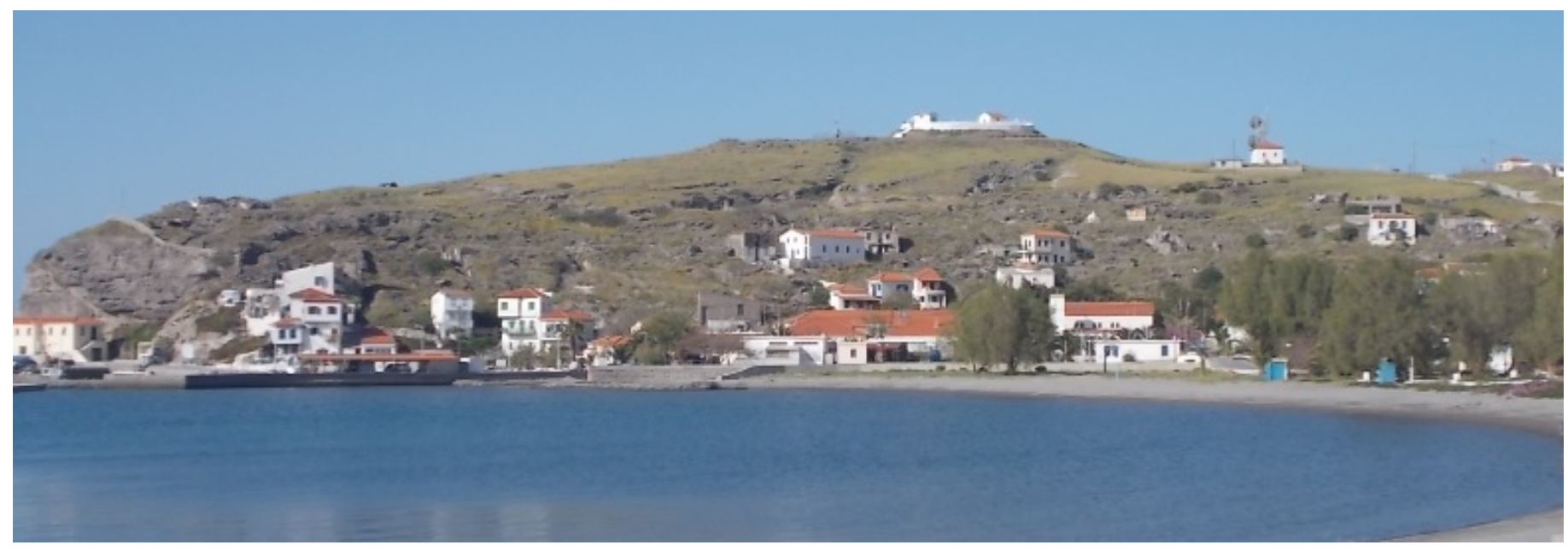

Fig 2. View of Agios Efstratios Island single settlement, 2019. Source: Photographic Archive of Athanasios Tatsis. 


\section{Research on the Desired Vision of Local Society}

The development of a geographically isolated small island, such as the study area, in a world dominated by Homo Economicus (Ordine, 2013; Persky, 1995) at times where everything is valued in investment benefit, seems very difficult. To achieve this, a different development plan is required and, particularly, a holistic plan able to face the island's issues in a more integrated way, utilizing its characteristics, satisfying the needs and desires of the local community.

In order to clarify the above needs, interviews were carried out as part of a research for the Interdisciplinary Program of Postgraduate Studies (IPPS) "Environment and Development" of the National Technical University of Athens (NTUA). A representative sample of one hundred and twenty nine questionnaires from permanent and temporary residents were completed, where concerns were expressed, specificities of the island became known and desired actions for a better future, their future, were indicated. At the same time, communication with involved development agencies, such as the local authorities, indicative political parties, the Ministry of National Defense, Agricultural University of Athens, Holy Monasteries of Megisti Lavra, Agios Dionysios and Karakallou that hold significant land on the island [Ai Stratis. Photographic Traces (1940-1970), 1999, p.188], the Center for Renewable Energy Sources of Greece and other bodies, have highlighted the need for cooperation and multidisciplinary consultation for the determination of the optimal development plan.

The people of Agios Efstratios, as participants in the consultation conducted in the study area and beyond, are not looking for something utopian. They envision a place that will not have to abandon again in the future, after the last devastation and re-occupation since 1.540AD (Giannos, 1983, pp. 86, 90). They dream of a place of equal opportunities, a place of social cohesion and welfare, a satisfying residential environment, their pre-earthquake cultural identity. Undoubtedly, the conditions were never easy on the island. Both natives and displaced people were struggling in harsh conditions on a daily basis, relying on their own forces and collective work for survival on this isolated island (Varnalis, 2014, pp. 19-23, 90-91). In an awakening attempt, deriving from history lessons, it is considered that their prosperity and the resolution of critical island issues require an alternative developmental approach, as documented above.

Based on the values of Worth-Living Integrated Development, the desired vision, as a result of consultation with the local community, is to make Agios Efstratios a self-sufficient place, a place of social cohesion and welfare, an island worthy of living.

\section{Restrictions - Problems and Developmental Perspectives of Agios Efstratios Island}

\subsection{Political Reality}

Agios Efstratios is distinguished by important dependencies that make it necessary to apply specific settings to ensure a satisfactory life quality level of the residents (Strategic and Operational Program of Agios Efstratios Municipality 2015- 
2019,2015, p.27). The inherent limitations and dependencies extend to the wider geographic area. The Peripheral Unity of Lemnos, where the island administratively belongs, is the most remote part of the North Aegean Region, which is one of the poorest regions of Greece and, by extension, one of the poorest of the EU (North Aegean Regional Operational Program 2015-2019, 2015, p. 6).

The development axes of the North Aegean Regional Operational Program as well as the Strategic Program of Agios Efstratios Municipality are general approaches, without focusing on local characteristics and needs. No major issues are, essentially, taken into account, such as population shrinking, income reduction, lack of basic infrastructure or subsistence. There are no support measures defined for vulnerable social groups or strengthening the productive sectors to combat unemployment or the effective use of historical and cultural reserves and incentives to attract people for permanent residence.

Nevertheless, the existence of social, environmental and development structures in the Region that can be utilized for the island's benefit is an important advantage. Additionally, Agios Efstratios, as an island-municipality, has the autonomy needed for policy making purposes. Moreover, it holds a relatively high reserve, therefore is an economically healthy Greek municipality, which provides extra perspectives and advantages (Strategic and Operational Program of Agios Efstratios Municipality 2015-2019, 2015, pp. 38, 47).

\subsection{Social Reality}

A gradual population decrease is noted on the island, especially after the 1968 earthquake, classifying it in Greek islands with the worst reduction in the last sixty years (Spilanis \& Kizos, 2015).

Table 1. Population Change of Agios Efstratios Island, 1951-2011

\begin{tabular}{|l|l|}
\hline \multicolumn{1}{|c|}{ YEAR } & \multicolumn{1}{c|}{ POPULATION } \\
\hline 1951 & 3.849 (along with the exiled ones) (1.170 inhabitants) \\
\hline 1961 & 1.061 (along with the exiled ones) (952 inhabitants) \\
\hline 1971 & 422 \\
\hline 1981 & 296 \\
\hline 1991 & 286 \\
\hline 2001 & 307 \\
\hline 2011 & 270 \\
\hline
\end{tabular}

Source: Ai Stratis. Photographic Traces (1940-1970), 1999 \& Hellenic Statistical Authority, 1991, 2001, 2011a 
Table 2. Permanent Population of Agios Efstratios Island by Sex and Age Groups, 2011

\begin{tabular}{|l|l|l|l|}
\hline \multicolumn{1}{|c|}{ AGE GROUP } & MALE & FEMALE & TOTAL \\
\hline $0-9$ & 9 & 12 & 21 \\
\hline $10-19$ & 14 & 9 & 23 \\
\hline $20-29$ & 13 & 14 & 27 \\
\hline $30-39$ & 13 & 14 & 27 \\
\hline $40-49$ & 18 & 19 & 37 \\
\hline $50-59$ & 23 & 18 & 41 \\
\hline $60-69$ & 18 & 17 & 35 \\
\hline $70-79$ & 12 & 15 & 27 \\
\hline $80+$ & 10 & 22 & 32 \\
\hline Total & 130 & 140 & 270 \\
\hline
\end{tabular}

Source: Hellenic Statistical Authority, 2011a

With regard to vulnerable and special social groups, nearly $21 \%$ of the population consists of people with a lack of income (Strategic and Operational Program of Agios Efstratios Municipality 2015-2019, 2015, p.8). Developmental constraints include the lack of social care facilities, despite the high percentage of elder population. In health sector, serious problems are identified due to understaffing, equipment shortages and the non-final integration of the island into the National Telemedicine Network, despite initial projections (National Telemedicine Network, 2015, pp. 33-34). In education sector, there are also problems of understaffing and infrastructure deficiencies that impede the educational work.

Referring to the social reality problems, as found during field research, there is a lack of substantial cooperation, volunteering and participation by the majority of Agios Efstratios people even for serious problems of common interest, such as the recent fight against locusts (BBC, 2017). Nevertheless, donations and contributions from non-profit institutions and volunteers from all over Greece cover significant gaps in areas with government deficits, such as health, education and sport activities.

\subsection{Economic Reality}

The high percentage of economically inactive population, which amounts to $70.74 \%$ (Hellenic Statistical Authority, 2011b), indicates a lack of job opportunities capable of attracting new people. An important employment prospect derives from the project 'Ai Stratis - Green Island' for attracting new researchers and scientists (CRES, 2016; Tselepis \& Nikoletatos, 2014). Similarly, significant prospects arise from the substantial exploitation of the alternative tourism sector, which is now largely untapped.

A particular feature for the island is the definitive abandonment of agricultural land, from the mid-1970s, with few exceptions near the settlement [Ai Stratis. Photographic Traces (1940-1970), 1999, p.189]. The peculiarity of Agios Efstratios lies in the fact that the abandonment of agriculture was not a continuous process, as in other small Aegean 
islands. On this island, there has been a sharp change from thriving primary production, pre-seismically, in a state of decline after the earthquake (Lalenis, 2010, p. 177). Therefore, cultivation of cereals, famous legumes and viniculture of the recent past have disappeared, while today there is a significant amount of underproductive and degraded land used as pastures [Ai Stratis. Photographic Traces (1940-1970), p. 188; Lalenis, 2010, p. 177]. The abandonment of these cultivations, combined with the lack of lowland areas, are major inhibitors of agricultural restructuring.

However, there are opportunities for traditional cultivations revitalization, according to the standards of the past. The dry or non-irrigated crops that few inhabitants still apply, fit into island's microclimate and eventual revival would provide significant prospects. The restoration of the abandoned drystone walling would reinforce traditional agriculture and prevent soil erosion, promoting the intangible cultural heritage (Intangible Cultural Heritage, 2014). Additionally, it is an opportunity to take advantage of existing indigenous knowledge for traditional crops, using local seed varieties maintained at the Agricultural University of Athens, according to the survey conducted.

The island has developed farming, exporting livestock (lambs and goats) to Lemnos Island, Kavala and Athens. Nevertheless, uncontrolled grazing degrades pasture quality, adversely affecting future productive sectors, such as the herbs and aromatic planting, which can provide growth prospects (Axiotis et al, 2018). Additionally, the absence of farmer cooperative, a small capacity abattoir and cheese dairy are inhibiting growth factors.

Regarding to fisheries, there is a serious development restriction due to fish reduction with increasing tendency, as a result of overfishing and illegal fishing (WWF Greece, 2015, pp.56-59; Elafros, 2015). The obligation to harmonize with the EU Marine Spatial Plan 2014/89 / EU by 2021 (EUR-Lex, 2014) is an opportunity to delimit island's fishing areas for the viability of local fishing and the marine ecosystem.

The manufacturing sector is absent from the island, constituting a development constraint. However, minimal anthropogenic interventions have kept the environment unchanged, giving a significant advantage to the implementation of organic farming, livestock and certification programs (Strategic and Operational Program of Agios Efstratios Municipality 2015-2019, 2015, p.26, 27).

There is lack of basic infrastructure on the island, such as an oven, a fishing or a butcher's shop, a pharmacy, a gas station and others, with negative impact on its attractiveness. In addition, the negative publicity about locusts in the international media (BBC, 2017), which was effectively handled by the Agricultural University of Athens nowadays, was also detrimental to the island's attractiveness. However, the natural landscape, local sights, vernacular architecture of the old settlement remains, the tranquil pace of life and the historicity of the place, are important incentives for mild tourist development, through promotion of its alternative forms followed by appropriate media coverage.

\subsection{Natural Environment}

The semi-mountainous morphology and geomorphology of the island, its inclusion in the European Natura 2000 list as a site of Community Importance GR4110002 and the important bird species in the Special Protection Area GR4110014 (European Environmental Agency, 2019), the marine biodiversity in Posidonia Oceanica meadows (Akritopoulou et al., 2008), the ecological value of the island (Filotis, 2020), local points of interest and the unobstructed view, provide significant development prospects. The high conservation level of the natural environment and its undeniable value make Agios Efstratios one of the best preserved ecosystems in the Aegean. However, the recent threat from Moroccan 
grasshopper (Dociostaurus maroccanus), which declared the island in an emergency situation in 2017, demands readiness of the Authorities for possible future environmental degradation.

\subsection{Anthropogenic Environment}

The event that marked island's evolution in recent years was the devastating $7.1 \mathrm{M}$ earthquake with 22 victims on the $20^{\text {th }}$ February 1968 and the following dramatic changes. The earthquake caused extensive destruction in the five hundred building settlement of traditional Aegean vernacular architecture (Giannos, 1983, p. 118), while almost all of the inhabitants were left homeless (Lalenis, 2010, p. 177)]. For immediate housing, the most inappropriate place was chosen by the ruling Dictatorial regime in Greece at that time, which was the often flooded neighboring valley [Ai Stratis. Photographic Traces (1940-1970), 1999, p. 213].

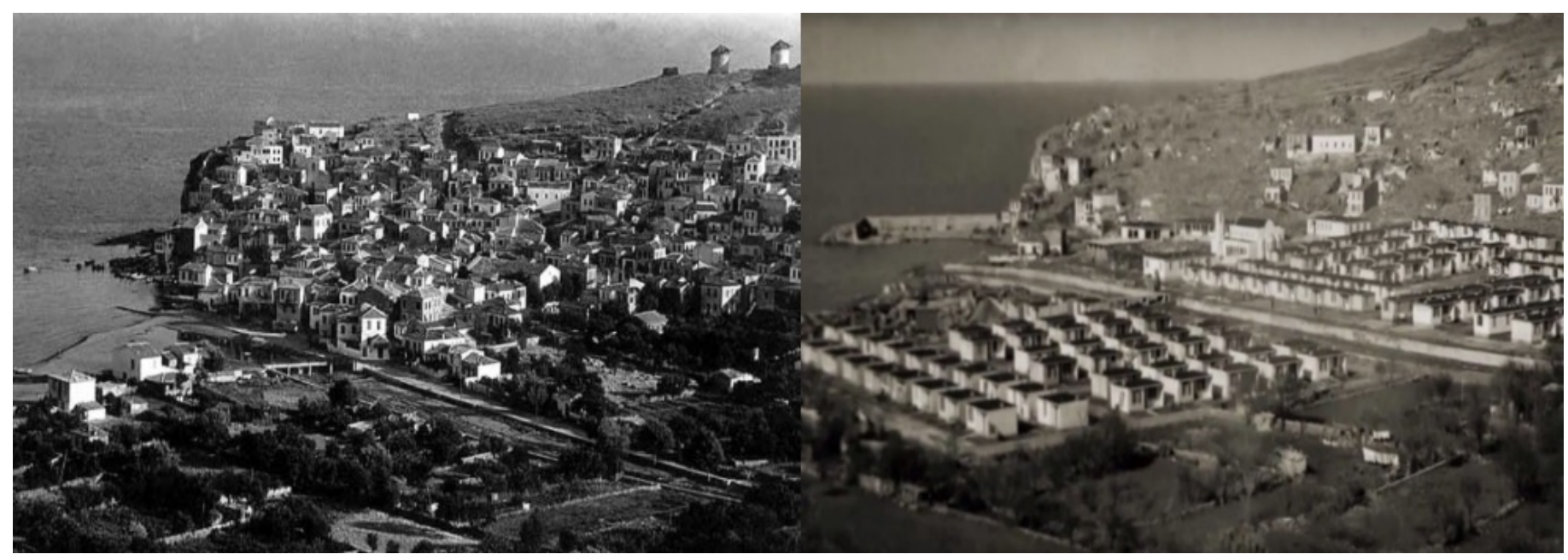

Fig 3. The pre-earthquake village (1959) and the new settlement of Agios Efstratios (1969). Source: Photographic Archive of Vasilis Manikakis.

The new settlement consisted of 185 low-function houses in a normalized configuration and occupied a big part of the fertile valley, a life source for the inhabitants (Giannos, 1983, p. 121). Additionally, the Dictatorship proceeded to demolition and expropriation of the old settlement, forbidding the reconstruction [Ai Stratis. Photographic Traces (19401970), 1999, p.213]. It is a historical fact that the settlement was not completely destroyed by the earthquake and most of the houses had not collapsed (Lalenis, 2010, p. 155). On the contrary, the demolition imposed by the Regime was total, with bulldozers and dynamite, without respect to local civilization and traditional architecture, demolishing about 400 houses and 8 churches, while today only 15 houses and 2 churches are preserved (Lalenis, 2010, p. 160). 


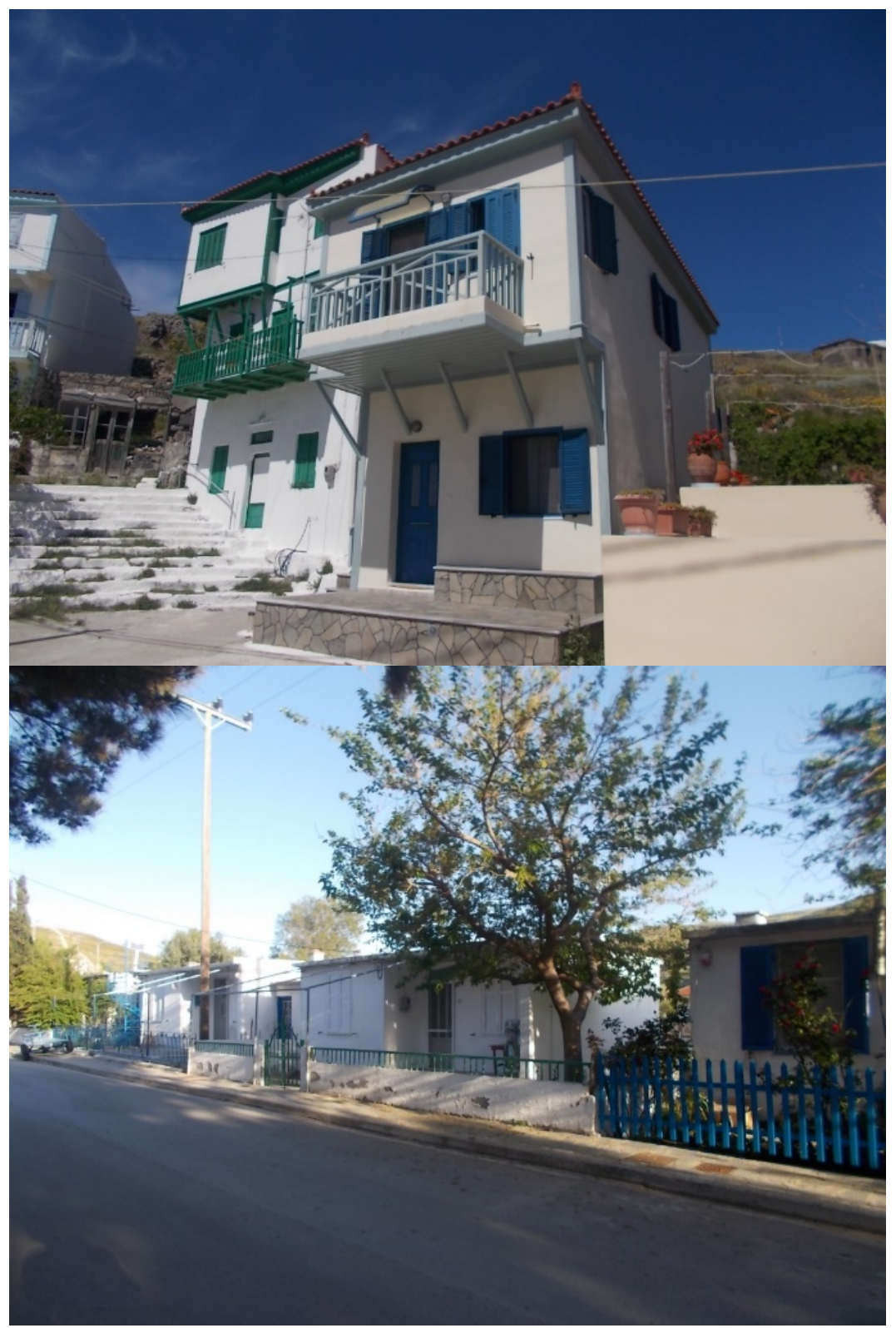

Fig 4. Houses of pre-earthquake village and after-quake settlement of Agios Efstratios, 2019. Source: Photographic Archive of Athanasios Tatsis.

The speed for immediate restoration did not solve earthquake problems. Instead, it accumulated new suffering (Ai Stratis. Photographic Traces (1940-1970), 1999, p. 213). The arbitrary and rigorous affiliation to specific 'rehabilitation' measures removed the ability of the local community to self-act. If interventions to repair the damaged buildings had been initiated, the traditional settlement, one of the most beautiful of the North Aegean, would have been saved (Lalenis, 2010, p. 160).

The gradual effects on the social fabric were catalytic (Eptakoili, 2015). The loss of housing meant the violent interruption of relations with the structured environment that reproduced the main memories and traditions for the inhabitants (Lalenis, 2010, p. 177; Giannos, 1983, p.118). Measures taken, such as the loss of house possession right for 
those who were not on the island the earthquake day, the granting of one home regardless the ownership in the old village and the random way of the new houses selection caused several problems. The concept of neighborhood was disorganized, negatively affecting social cohesion and enhancing island's abandonment by its inhabitants who could revive it [Ai Stratis. Photographic Traces (1940-1970), 1999, pp. 213, 216]. These interventions contributed decisively to the waning of economic life on the island, the collapse of the productive system and the abrupt abandonment of agricultural land. Furthermore, the Greek Military Junta's actions complicated the ownership regime in the old settlement as it was first demolished and then expropriated (Government Gazette 91/D/27.5.1968, 1968), creating ambiguity in the ownership boundaries (Lalenis, 2010, pp. 173, 177).

Regarding the development potentials of the anthropogenic environment, the declaration of the old settlement as traditional for its protection is worth mentioning (Government Gazette 171/ D /16-2-2005, 2005) as well as an effort to promote its public spaces (Strategic and Operational Program of Agios Efstratios Municipality 2015-2019, 2015, p. 12), with no results so far.

\subsection{Cultural Reality}

The island's history is significant, as a result of human presence evidence for over five thousand years (Giannos, 1983, p.66). Prehistoric (Sampson et al, 2018), Mycenaean, Archaic and Hellenistic period findings (Arhontidou-Argiri, 2005, p.115) indicate the importance of Agios Efstratios in Antiquity and the possible commercial activities with Poliochne of Limnos, Troy and Athens. Subsequent findings of Roman, Genoa and Ottoman domination, its annexation in the Monastery of Great Lavra as the 'island of the young beardless monks', the post-Byzantine monuments, as well as the monuments of modern history, such as Marasleios School, constitute its cultural heritage (Giannos, 1983, p.80-112). Moreover, the cultural wealth of the last century displaced people is important, as they were inspired on the island and created art that today are elements of the cultural life of Greece (Exile Museum, 2020). This untapped cultural wealth could turn the settlement into an open-air museum on the displaced trails (Democracy Museum, 2020) and transform the unfortunate distinction of an island for 'punished' people of the recent past to an island of struggle for social justice (Varnalis, 2014, p 19-23).

On the contrary, the 1968 earthquake and post-earthquake interventions caused the destruction of important monuments (Chora Pigadi, Holy Church of the Nativity of Christ) (Giannos, 1983, pp. 93, 121), the gradual disappearance of customs and traditions and affected negatively the cultural identity of the islanders (Tatsis, 2016).

\subsection{Technical - Technological Reality}

The road network is insufficient with just a $2.5 \mathrm{~km}$ asphalt section and poor quality dirt roads, making difficult the use of conventional vehicles out of the settlement. The regular connection with mainland (Lavrio, Kavala) and adjacent islands (Lemnos) provides a development perspective. However, the fifty-year-old local ship 'Aeolis' and the problems of the new port (Limnosreport.gr, 2016), need to be tackled for this vital sector. There is a heliport on the island in operational condition, but a significant development potential will be provided by the implementation of a water aerodrome. The recent construction of a refuse collection station for recyclable materials sorting provides a growth perspective, however, it should be put into operation before the new facilities are devalued. 
In the field of renewable energy, the re-integration of the 8.5 million euros research project 'Ai Stratis - Green Island' into the new NSRF with $100 \%$ EU funding is pioneering. The integration marks a new effort to create the first noninterconnected island of Greece, covering $85 \%$ of the electricity and district heating needs from renewable energy sources, spurring the world's scientific interest in this sector (Tselepis, 2014).

\section{Fifty Actions to the Worth-Living Integrated Development of Agios Efstratios Island}

According to the Worth-Living Integrated Development methodology, the definition of targeted actions requires an interdisciplinary approach. Therefore, with the limitations of certain scientific fields of the authors, but with strong criterion the wishes of the islanders for a better future, appropriate actions in political, economic, social, cultural, technical/ technological dimension and the environment, natural and anthropogenic, are listed below. These actions, acting supportively with one another, could contribute to the realization of their desired vision.

\section{Political Dimension}

1. Completion of cadastral and forest mapping of the island for creation of integrated cartographic and descriptive information.

2. Staffing of the Municipality in positions with basic deficiencies.

3. Collaboration with other islands with similar problems or potentials, like the Hellenic Small Islands Network, the Smart Islands Initiative and the European Small Island Federation.

4. Assistance to the Municipality's work by the Region and the Central Authorities for jointly addressing local issues and needs. Effort to reduce taxation to tackle inequality caused by insularity.

5. Utilization of $50 \%$ of the Municipality's reserve for actions described in this paper.

\section{Social Dimension}

6. Optimization of health prevention through integration into the National Telemedicine Network and creation of a Health Prevention Center.

7. Creation of social welfare benefits, such as a social pharmacy, a social grocery store and a day care center for elderly people to serve vulnerable social groups.

8. Financial and housing benefits by the Municipality for attracting staff to meet health and education needs.

9. Improvement of social cohesion, through participatory actions and volunteerism, with hospitality provision by the Municipality to the Marasleios School. Indicative actions are related to the revival of traditional crops, the restoration of drystone walling, the maintenance of a municipal vegetable garden, the establishment of annual sporting events such as off-road cycling and running and the fight against possible appearance of locusts.

10. Education, extroversion and teaching reinforcement to broaden the cognitive horizons of the local community for recovering and preserving social cohesion (Kantzara, 2016). 


\section{Economic Dimension}

11. Motivation for revitalization of traditional cultivations utilizing the new EU's Common Agricultural Policy subsidies for young farmers.

12. Reconstitution of a farmer cooperative, aiming at cooperation and development of negotiating dynamics for local products.

13. Cooperation with the Holy Monasteries of Mount Athos for the utilization of their land.

14. Creation of a small cheese dairy unit.

15. Study of a small capacity abbatoir establishment in order to deal with livestock transferring problems.

16. Fish products standardization study to address the fresh fish immediate transferring and disposal difficulties.

17. Development of organic apiculture for biological production of thyme, oak or flower honey.

18. Cultivation and standardization of aromatic plants and herbs.

19. Exploitation of the oak forest acorns, after elimination of the oak weed, for new products with technical applications similar to those of Kea Island (Oakmeal, 2020).

20. Certification and promotion of locally produced products beyond the local market.

21. Utilization of cultural, historical, hiking, gastronomic, natural, religious, educational and other forms of alternative tourism.

22. Organize diving events in sites of submarine antiquities or shipwrecks, such as the islet of Dodeka Apostoloi (Dive in Our Islands, 2020).

\section{Natural Environment}

23. Establishment of a ban zone for large foreign fishing vessels within the Special Protection Area GR 4110014, as well as, fishing prohibition for local fishermen around the islets of Velia, Dodeka Apostoloi and Tripiti cape, as important fish reproduction areas.

24. Protection of the four island wetlands (Government Gazette 229/AAP/ 19.06.2012, 2012), as ecosystems for biodiversity preservation.

25. Implementation of a management plan for grazing, regulating conditions of land use according to island's grazing capacity.

26. Effort for European certification of island's environmental interest hiking routes through the European Ramblers' Association (Leading Quality Trails - Best of Europe) (ERA, 2020).

27. Promotion of the unexplored Petrified Forest, the geological formations and the sand dunes of Alonitsi as elements of natural heritage for sightseeing purposes.

28. Creation of a travel and hiking guide of the island.

\section{Anthropogenic Environment}

29. Resolution of the complicated property regime that exists in the old settlement with the assistance of University Institutions or examination of possible land consolidation.

30. Motivation for restoration of the old settlement by providing low interest rate mortgages or other benefits by the Government. 
31. Transfer of Agios Efstratios Military Defense Administration from Limnos to Agios Efstratios for population growth in an already designated area.

32. Tile roof placement on post-earthquake buildings for aesthetic and energy upgrading.

33. Reconstruction of drystone walling for soil retaining and underground aquifer enrichment.

34. Infrastructures creation, such as an oven, a gas station, a pharmacy, a butcher and fishing shop in the Municipal Market, through incentives from the Municipality.

\section{Cultural Dimension}

35. Promotion of the island as a historical place of remembrance, as the longest place of displacement in Greece and "a symbol of the struggle for a society and times of happiness..." (Varnalis, 2014, p. 19).

36. Revitalization of traditions (customs, dances, songs, art), through the establishment of cultural events for the recovery of cultural identity.

37. Conduction of archaeological research, in view of the findings and the historicity of the place.

38. Creation of appropriate infrastructure at the historic Marasleios School in order to be used as a cultural and creative center of the local community and beyond.

39. Creation of an open-air museum on the traces of the displaced, through revealing points of the old camp.

40. Revival of cultural activities of displaced people, such as poetic afternoons, as well as the establishment of festival to honor exiled people who lost their lives on the island.

41. Restoration of the ecclesiastic monument of five Holy Martyrs church in the old village.

42. Creation of a folklore museum in Mytilia mansion and publication of unpublished folklore material kept at the Academy of Athens [Hellenic Folklore Research Center of the Academy of Athens, 03641, 1972 \& 04109, 1979].

43. Restoration of the old village windmills as important pre-industrial and cultural elements.

\section{Technical / Technological Dimension}

44. Asphalt of the dirt road leading to the monument of Lieutenant Sialmas and Agios Dimitrios beach with the assistance of the Ministry of National Defense.

45. Modernization of local connection with Lemnos by replacing the 50 year old ship 'Aeolis'.

46. Licensing and construction of water aerodrome for future interconnection with the mainland and other island destinations.

47. Creation of two water reservoirs to secure island's future water supply (Lialios, 2015).

48. Activation of the new waste transfer station.

49. Feasibility study of an offshore wind park development in Alonitsi for exploitation of significant wind potential (Regulatory Authority for Energy, 2020).

50. Implementation and promotion of 'Ai Stratis - Green Island' program (Zafirakis et al, 2012) with extension of the district heating infrastructure to the old settlement for future interconnection.

The proposed actions of this holistic approach are priorities of the local community, according to interviews carried out, questionnaire findings and wider research conducted. This is based on the fact that the participants (permanent and temporary residents) identified as crucial problems, among others, the aging of island's population, the lack of 
employment options, shortages in healthcare and welfare staff, shortages in technical and technological infrastructures, lack of agricultural production, cultural activities and entertainment, as well as insufficient connection to the mainland.

Therefore, enabling islanders to identify actions for their island development without numerical or other constraints, over $74 \%$ consider the restoration of the old traditional settlement necessary due to unsatisfactory residential environment and $70 \%$ the development of alternative forms of tourism to exploit the unique natural environment. Furthermore, about $60 \%$ consider the recovery of their pre-earthquake cultural identity important, as well as the promotion of island's rich history, tradition, culture and the creation or use of abandoned infrastructure for health, sport, educational or cultural activities. In addition, $57 \%$ of the participants propose the certification of local products and the revival of traditional crops in order to achieve nutritional self-sufficiency while, $54 \%$ wish to achieve energy self-sufficiency by utilizing the island's significant wind and solar potential. At the same time, more than $52 \%$ of the participants highlight the necessity to attract new people to live on the island in order to cope with the ongoing depopulation, due to the very low birth rate and the aging population.

It is worth mentioning that, despite the lack of effective cooperation on the island, as the islanders themselves point out, $34 \%$ are willing to contribute with work, $45 \%$ with knowledge and $10 \%$ with land supply to implement the actions required for their island development.

Undoubtedly, the rational opinions of local residents and their perception of development, including the values engrained therein, should be taken under serious consideration for the development of island areas (Park, 2016). Although, physical elements have been the focus of regional development, the ultimate goal remains the constant development of local communities (Shin and Park, 2014). Therefore, the establishment of an appropriate development policy and its effective implementation should be based on a precise analysis of the current state of local areas, in order to address the most fundamental and central problems identified by residents (Park, 2016).

Furthermore, according to Royle, as stated by Hong (2019), an island is a special space where humans and nature use marine resources to live in a confined area surrounded by the sea, therefore, it is very difficult to combine sustainability assessments applicable to inland. An island is an area where complex multilevel environmental/ society/ economic issues increase rapidly, including uncertainty of economic growth, low growth and low consumption, rapid depopulation, aging and uninhabited conditions (Hong et al, 2018). An island is like a living organism where biocultural diversity and ecosystems interact. The maritime history of humans confirms that the culture of the island regions depends on natural resources that currently are being threatened, among others, by the rapid changes in climate and marine environment, instability in natural disasters and reckless resource development (Hong G., 2018).

The particular culture and identity of each island that derives from the traditional ecological knowledge of its inhabitants (Hong G., 2018), makes it difficult to investigate, analyze and assess sustainability of these islands, according to Kakazu as stated by Hong (2019). In order to understand and study an island diversely, beyond the disciplinary boundaries of the humanities, social and natural sciences (Hong et al., 2018), mutual cooperation and a multidisciplinary viewpoint is important (Nakagoshi and Hong, 2001; Hong, 2007; Baldacchino, 2019).

Especially for small and isolated islands, a holistic and interdisciplinary approach is required, which aims to address current development deficiencies. The holistic approach of the Worth-Living Integrated Development, which is described in this paper, could fill these gaps for an effective development plan for small remote islands or other study areas with similar characteristics. 


\section{Conclusions - Discussion on Further Research}

The island of Agios Efstratios plays an important role for Greece due to its proximity to the Dardanelles, its historical and political importance, its natural wealth and cultural heritage. However, as this paper documents, it faces substantial problems that the country, in the current period of multidimensional crisis and economic hardship, has been slow or unable to cope.

Despite the fact that small isolated islands of Greece contribute in the protection of marine sovereignty and the respect of national security, as well as the larger ones, the dominant economic model has not succeeded in hindering their population reduction, even in times of economic growth. The one-dimensional, concentrative and fragmentary economic growth of urban areas, does not simultaneously ensure the real development for the majority of the poor, less-favoured peripheral regions, as well as for its habitants.

Furthermore, regional development cannot be the same for every region. According to McCall, as stated by Azzopardi (2015), purely 'economical' approaches to the study of small island worlds have limitations and distort the real image if researchers become indifferent to real concerns of real people in real time. In understanding the real needs of the local community, the consultation and experience of researchers in the study area is crucial. Consultation through participatory processes with the inhabitants of the study area is the focal point and the essential precondition for the best possible and effective development plan (Rokos, 2007).

The present study emphasizes the need of creating a truly integrated framework for the development of small isolated islands like Agios Efstratios, which is largely absent from the studies of the Aegean islands (Karampela et al., 2017). The technological tools, the methodological and technical steps and the optimal policy practices for the pursuit of the WorthLiving Integrated Development include interdisciplinarity and the need for holistic approach, inventory and mapping of the elements, features, appearances, phenomena and facts, which constitute the - unique in each case - unity of natural and socio-economic space (Geronteli \& Michailidou, 2010).

This holistic framework deepens in the study of the integrated surveys (as well as their multidimensional relationships, interdependences and interactions) and systematic monitoring of their changes through time in order to utilize all perspectives, even those not easily discernible. Among others, the methodology is seeking to revive good practices of the past and utilization of indigenous knowledge to identify actions that will not contradict each study area's specific features However, we highlight the limitations of this case study regarding interdisciplinarity, due to authors' certain scientific fields.

Despite the development constraints of Agios Efstratios and other small isolated islands, the country has a moral debt to halt their continuing shrinking. Nevertheless, it should be understood that local societies should be actively involved in that purpose. Local administration units as well as citizen initiatives, should participate actively in the implementation of a local action plan, since they are the only ones who really know the actual potential, peculiarities, problems, limitations, priorities and expectations of their territory. An integrated development requires a culture of collaboration and team spirit, which is not always self-evident. It is necessary to strengthen the participatory spirit where it exists and to cultivate it where this does not exist (Chapman, 2011). Many approaches recognize that 'cooperation' and 'networking' are important for islands, where human resources are often limited, and within different social groups (Karampela et al, 2017). 
Given the lack of foreign literature and the limited Greek bibliography for the study area, this paper may be a trigger for further study and research on the region and other small island regions with similar characteristics. At the same time, through this paper, appropriate development actions for Agios Efstratios Island are indicated as well as the seven steps methodology of Worth-Living Integrated Development, in order to form a useful tool for developmental designers. A tool with different perspectives on island development, concerning researching, understanding and planning that takes under serious consideration the right to the island (Clark, 2013).

Undoubtedly, the implementation is not easy but, probably, it is one-way solution for integrated development and, at the same time, the culmination of the human pursuit which is to live a worthy life, from the small society of Agios Efstratios Island to the largest scale, our global society.

\section{References}

Ai - Stratis. Photographic Traces (1940-1970), 1999. Vasilis Manikakis Archives, texts by Giorgos Nikolakakis, Ministry of the Aegean, Directorate of Culture, Mytilene. (In Greek)

Akritopoulou, E., Gerovassiliou, V., Koutsoumpas, D., 2008. The sea richness of Agios Efstratios: Sustainable Development Possibilities. Available at: http://aistratis-nature.blogspot.com/2008/11/blog-post.html. (In Greek). Last access 29/2/20

Alatzas S., Badogiannis N., Giannopoulou C., Glynos L., Koukouvinou A., Liolios M., Livadaras N., Merkoureas - Karras A., Tatsis A., 2016. Integrated Development of the South Aegean Region - Regional Unity of the Cyclades. IPPM of the NTUA “Environment and Development”, Athens. (In Greek)

Arhontidou-Argiri, A. 2005. Aghios Efstratios In: A. Vlahopoulos, (ed). Archaeology-Aegean Islands. Melissa Publishing House, Athens.

Axiotis E, Halabalaki M and Skaltsounis LA, 2018. An Ethnobotanical Study of Medicinal Plants in the Greek Islands of North Aegean Region. Front. Pharmacol. 9:409. https://doi.org/10.3389/fphar.2018.00409

Azzopardi, J., 2015. Solving problems, the island way: human resourcefulness in action among the islanders of Gozo. Island Studies Journal, Vol. 10, No. 1, 2015, pp. 71-90

Baldacchino, G., 2019. How far can one go? How distance matters in island development. Island Studies Journal, Vol. 15, No. 1, 2020, pp. 2542. Island Studies Journal. DOI: 10.24043/isj.70

BBC News, 2017. Greece battles locust plague on Agios Efstratios Island. Available at: https://www.bbc.com/news/world-europe-39972713? SThisFB. Last access: $29 / 2 / 20$

Chapman D., 2011. Inside Outside: spatial planning and small islands. Center for Environment and Society Research Working Paper Series no. 7, Birmingham City University.

Clark, E., 2013. Financialization, sustainability and the right to the island: A critique of acronym models of island development. Journal of Marine and Island Cultures (2013) 2, 128-136

CRES, 2016. Technical Description of the project “Green Island-Ai Stratis”, 2nd edition. Center for Renewable Energy Sources. (In Greek)

Deidda, M. 2016. Insularity and economic development: a survey. International Review of Economics 63, $107-128$.

https://doi.org/10.1007/s12232-015-0238-8

Democracy Museum, 2020. Agios Efstratios. Available at: http://www.mouseiodimokratias.gr/english/index.asp. Last access: 28/2/20 
Dive in our Islands, 2020. Dodeka Apostoloi. Agios Efstratios. Available at: http://www.diveinourislands.com/en-us/Lesvos-Lemnos/DodekaApostoloi-Ag-Efstratios. Last access: 29/2/20

Elafros, J., 2015. Overfishing empties the Mediterranean. Kathimerini.gr. Available at: https://www.kathimerini.gr/802685/article/epikairothta/perivallon/h-yperalieysh-adeiazei-th-mesogeio (in Greek). Last access 28/2/2020

Emke - Poulopoulou, H, 2018. The Population of Greece under Persecution. Under the auspices of the Hellenic Society for Demographic Studies, Vogiatzi Publications. (In Greek)

Eptakoili T., 2015. The adventure of Ai Stratis. Kathimerini.gr. Available at: https://www.kathimerini.gr/827457/article/epikairothta/ellada/hperipeteia-toy-ah-strath. (In Greek). Last access 29/2/2020

ERA, 2020. European Ramblers Association (ERA - EWV - FERP). Available at: https://www.era-ewv-ferp.org/lqt/. Last access: 29/2/20

ESPON, 2013. The Development of the Islands: European Islands and Cohesion Policy (EUROISLANDS), Final Report. ESPON \& University of the Aegean. Available at: https://europeansmallislands.files.wordpress.com/2017/03/espon-euroislands-report-2013.pdf. Last access: 28/2/20

EUR-Lex, 2014. Access to European Union Law. Document 32014L0089. Directive 2014/89/EU of the European Parliament and the Council of 23 July 2014 establishing a framework for maritime spatial planning. Official Journal of the European Union. https://eur-lex.europa.eu/legalcontent/EN/TXT/?uri=CELEX\%3A32014L0089. Last access: 28/2/20

EUR-Lex, Joined Cases T-6/92 and T-52/ 92, 1993. Access to European Union Law. Document 61992TJ0006. Judgment of the Court of First Instance (Fourth Chamber) of 26 October 1993. Andreas Reinarz v Commission of the European Communities. European Court Reports 1993 II-01047. ECLI identifier: ECLI:EU:T:1993:89. Available at: https://eur-lex.europa.eu/legal-content/EN/TXT/PDF/? uri=CELEX:61992TJ0006\&from=EN. Last access: 28/2/20

EUR-Lex, Case 8/82, 1983. Access to European Union Law. Document 61982CJ0008. Judgment of the Court (First Chamber) of 23 February 1983. Storage costs for sugar - Flat-rate reimbursement. European Court Reports 1983 -00371. ECLI identifier: ECLI:EU:C:1983:41. Available at: https://eur-lex.europa.eu/legal-content/EN/TXT/PDF/?uri=CELEX:61982CJ0008\&from=EN. Last access: 28/2/20

European Environmental Agency, 2020. Natura 2000 Network Viewer. Available at: http://natura2000.eea.europa.eu/? query=Natura2000Sites_9883_0,SITECODE,GR4110002. Last access: 29/2/20

Exile Museum, 2020. Available at: http://www.exile-museum.gr/. (In Greek). Last access 29/2/20

Filotis, 2020. Database for the Greek Nature, National Technical University of Athens, Department of Water Resources \& Environment. Available at: http://filotis.itia.ntua.gr/biotopes/c/GR4110002/. (In Greek). Last access 29/2/20

Geronteli A. \& Michailidou E., 2010. Implementing the theory of Worth Living Integrated Development. Metsovion Interdisciplinary Research Center (M.I.R.C.) of the N.T.U.A. Available at: http://old.ntua.gr/MIRC/publications/geronteli-michailidouimplementing_the_theory_of_worthliving_integrated_development_(2010).pdf. Last access 29/2/20

Giannos, I., 1983. History of Agios Efstratios Island (Ai - Stratis), from ancient times until today, Chryssi - Alonissos - Nea - lera. Gutenberg, Athens. (In Greek)

Government Gazette (229 / AAP / 19-06-2012), 2012. Approval of a list of small island wetlands and setting conditions and restrictions for the protection and promotion of the small coastal wetlands included in it. Issue of Urban Exploitation and Urban Planning. (In Greek)

Government Gazette (171 / D / 16.02.2005), 2005. Designation of a part of the settlement of Agios Eustratios in the prefecture of Lesvos traditional, establishment of a protection zone in the rest of the settlement and determination of special conditions and limitations for their construction. (In Greek)

Government Gazette (91 / D / 27.05.1968), 1968. On the compulsory expropriation of real estate in the area of Agios Efstratios Lesvos to restore earthquake-stricken people. (In Greek)

Hellenic Folklore Research Center of the Academy of Athens, 03641, 1972. Folkloric of Agios Efstratios Island. Giannos I., Agios Efstratios. (In Greek) 
Hellenic Folklore Research Center of the Academy of Athens, 04109, 1979. Folklore material of Limnos. Manakas G., Limnos. (In Greek) Hellenic Statistical Authority, 2011a. Real Population of Greece at the census of February 2011. Available at: https://www.statistics.gr/el/statistics/-/publication/SAM03/2011. (In Greek). Last access 29/2/20

Hellenic Statistical Authority, 2011b. Population Census 2011, table B02, permanent population by gender and occupation. Available at: https://www.statistics.gr/el/statistics/-/publication/SAM04/-. (In Greek). Last access 29/2/20

Hellenic Statistical Authority, 2001. Real Population of Greece at the census of March 18, 2001. Available at: https://www.statistics.gr/el/statistics/-/publication/SAM03/2001. (In Greek). Last access 29/2/20

Hellenic Statistical Authority, 1991. Real Population of Greece at the census of March 17, 1991. Available at: https://www.statistics.gr/el/statistics/-/publication/SAM03/1991. (In Greek). Last access 29/2/20

Hong, S.K., 2019. The Role of Ecological Diversity and Identity for Sustainable Development of Islands. Journal of Marine and Island Cultures, v8n1. DOI: 10.21463/jmic.2019.08.1.04

Hong, G., 2018. Islands of enclavisation: Eco-cultural island tourism and the relational geographies of near-shore islands. Area 50: 1 9.

Hong, S.K., Won, Y.T., Lee, G.A., Han, E.S., Cho, M.R., Park, H.Y., Kim, J.E., Chisholm Hatfield, S., 2018. Interdisciplinary Convergence Research Design on Island Biocultural Diversity-Case Study in Wando-gun (County) Island Region, South Korea. Journal of Marine and Island Cultures, 7(1): 12-37.

Hong, S.K., 2007. Linking man and nature landscape systems: landscaping Blue-Green network, in: Hong, S.K., Nakagoshi, N., Fu, B., Morimoto, Y. (Eds.), Landscape ecological applications in man influenced areas: linking man and nature systems, Springer, Dordrecht, pp.505-523.

Intangible Cultural Heritage, 2014. The art of dry stone walling. http://ayla.culture.gr/en/i_texni_tis_xerolithias/. Last access: 29/2/20

Kantzara, V., 2016. The relation of Education to Social Cohesion. Social Cohesion and Development, 6 (1), 37-50, https://doi.org/10.12681/scad.8973

Karampela, S., Papazoglou, C., Kizos, T., \& Spilanis, I., 2017. Sustainable local development on Aegean Islands: a meta-analysis of the literature. Island Studies Journal, Vol. 12, No. 1, 2017, 71-94. https://doi.org/10.24043/isj.6

Koroneos C.J. and Rokos D., 2012. Sustainable and Integrated Development - A Critical Analysis. Sustainability, 4(1), 141-153, https://doi.org/10.3390/su4010141.

Koutsopoulou A., 2013. Dynamics of island systems: Towards a strategy of integrated development of the Greek micro-space. 11th Regular Scientific Conference. Greek Section of the European Regional Science Association (ERSA-GR). Available at: http://grsa.prd.uth.gr/conf2013/37_koutsopoulou_ersagr13.pdf (In Greek). Last access: 28/2/20

Lalenis, K., 2010. Agios Efstratios before and after the earthquake of 1968: Reconstruction in Extreme Island Isolation Conditions. Paper in Beriato, H. and Delladecima P-M, "Earthquakes and Residential Development. The Role of Architectural, Urban and Spatial Planning”, Kritiki Publications, Athens. (In Greek)

Leemans R., 2012. Global-change research to understand, handle problems of a Planet under Pressure. Current Opinion in Environmental Sustainability, 4: 1-2, Elsevier. DOI: 10.1016/j.cosust.2012.02.001

Lialios G., 2015. "How to quench 20 island's thirst in the Aegean”. Kathimerini.gr. Available at: https://www.kathimerini.gr/816628/article/epikairothta/ellada/pws-8a-3ediyasoyn-20-nhsia-sto-aigaio. (In Greek). Last access 29/2/20

LimnosReport.gr, 2016. This is the new, safe harbor of Agios Efstratios! Available at:

https://www.limnosreport.gr/eidiseis/92065/\%CE\%B1\%CF\%85\%CF\%84\%CF\%8C-\%CE\%B5\%CE\%AF\%CE\%BD\%CE\%B1\%CE\%B9-

\%CF\%84\%CE\%BF-\%CE\%BD\%CE\%AD\%CE\%BF-\%CE\%B1\%CF\%83\%CF\%86\%CE\%B1\%CE\%BB\%CE\%AD\%CF\%82-

\%CE\%BB\%CE\%B9\%CE\%BC\%CE\%AC\%CE\%BD\%CE\%B9-\%CF\%84\%CE\%BF\%CF\%85-\%CE\%B1/. (In Greek). Last access 29/2/20 
Linardaki, M., 2016. "The Greek population is shrinking dangerously". Neakriti.gr. Available at: https://www.neakriti.gr/article/eidiseis/1347484/syrriknwnetai-epikindyna-o-ellinikos-plithysmos/. (In Greek). Last access: 28/2/20

Nakagoshi, N., S.K. Hong, 2001. “Vegetation and Landscape Ecology of East Asian 'SATOYAMA”', Global Environ. Res. 5(2): 171-181

National Telemedicine Network, 2015. 2nd Administration of Health Region Piraeus and the Aegean. Ministry of Health. Call for competition. Available at:

https://www.2dype.gr/images/stories/diakirixeis/\%CE\%94\%CE\%99\%CE\%91\%CE\%9A\%CE\%97\%CE\%A1\%CE\%A5\%CE\%9E\%CE\%97_\%CE\%95\%CE \%94\%CE\%99\%CE\%A4_2\%CE\%B7\%CF\%82_\%CE\%A5\%CE\%A0\%CE\%95_\%CE\%A0\%CE\%95\%CE\%99\%CE\%A1\%CE\%91\%CE\%99\%CE\%A9\%CE\%A3_\% CE\%9A\%CE\%91\%CE\%99_\%CE\%91\%CE\%99\%CE\%93\%CE\%91\%CE\%99\%CE\%9F\%CE\%A5.pdf. (In Greek). Last access: 29/2/20

North Aegean Regional Operational Program 2015-2019, 2015. Phase A, Strategic Planning. Available at: https://www.pvaigaiou.gov.gr/dyn/userfiles/files/pdf-stratigikos-sxediasmos/stratigikos-sxediasmos-2015-2019.pdf (In Greek). Last access: $29 / 2 / 20$

Oakmeal, 2020. Acorn Initiative in Greece. Available at: https://www.oakmeal.com/. Last access: 29/2/20

Ordine, N., 2014. The usefulness of the useless. Manifesto. Translated by Chrisostomidis I, Agra Publications, Athens. (In Greek)

Park, S.-H., 2016. A strategic approach to policy tasks for the development of Korea's island areas. Journal of Marine and Island Cultures (2016) $5,14-21$

Pavlides S.B. \& Tranos M.D., 1991. Structural characteristics of two strong earthquakes in the North Aegean: lerissos (1932) and Agios Efstratios (1968) Journal of Structural Geology, Volume 13 Issue 2, Pages 205-214, Elsevier. https://doi.org/10.1016/0191-8141(91)90067-S

Persky, J., 1995. Retrospectives: The Ethology of Homo Economicus. The Journal of Economic Perspectives - Volume 9, Number 2, Spring 1995, Pages 221-231. DOI: 10.1257/jep.9.2.221

Pugh, J., 2013. Speaking without Voice: participatory planning, acknowledgment, and latent subjectivity in Barbados, Annals of the Association of American Geographers 103:5 1266-1281. https://doi.org/10.1080/00045608.2012.706571

Regulatory Authority for Energy (RAE), 2020. Geospatial map for energy units \& requests. Available at: http://www.rae.gr/geo/?lang=EN. Last access: $29 / 2 / 20$

Rokos, D., 2007. The Integrated Development of Epirus. Problems, Capabilities and Limitations. 4th Interdisciplinary Interuniversity Conference of the NTUA and the MIRC of the NTUA "The Integrated Development of Epirus", Conference Center of Metsovo, 23-26 September 2004. Scientific Editing: Rokos D. Publishing House of A.A. Livanis, pp. 93-140, Athens. (In Greek)

Rokos, D., 2004. The Integrated Development of Mountain Areas. Theory and Practice. Proceedings of the 3rd Interdisciplinary Interuniversity Conference "The Integrated Development of Mountain Areas. Theory and Practice", NTUA-Municipality of Metsovo, 7-10 June 2001, Metsovo Conference Center, Metsovo, Scientific Research Prof. D. Rokos, Alternative Publications, pp. 79-140, Athens. (In Greek)

Rokos, D., 2003. From "sustainable" to the Worth Living Integrated Development. A.A. Livanis Publishing Organization, p. 551, Athens. (In Greek)

Sampson, A., Kabouroglou, E., Kaczanowska, M., Kozlowski, J.K., 2018. Presence of Neanderthals on the Island of Agios Efstratios and Probable Networks of Contacts in the Northeastern Aegean during the early Middle Palaeolithic. Annals of Archaeology. Volume 1, Issue 1, 2018, pp. 39-56

Shin, S.-H., Park, S.-H., 2014. A study of the change in consciousness among island residents in Korea related to policy: using the survey of resident consciousness in 1995 and 2011. I. Cult. 44, 203-235 (in Korean with English abstract).

Spilanis G. and Kizos Th., 2015. Atlas of the Islands. Department of Environment and Department of Geography, University of the Aegean. Mytilene. (In Greek)

Spilanis G., Kondili J., Gryllaki S., 2003. Measuring the Attractiveness of Small Islands. A Tool for Sustainability. Paper Submitted for Presentation at the International Conference on Sustainability Indicators/ Organized by The Islands and Small States Institute/ University of 
Malta/ Foundation for International Studies, Valletta, Malta/ 6-8 Nov 2003. Available at:

http://www1.aegean.gr/lid/internet/elliniki_ekdosi/Dimosieuseis/Malta_paper.pdf. Last access: 29/2/20

Stavropoulos, D., 2015. Small islands are "emptied" by residents. Paraskhnio.gr. https://www.paraskhnio.gr/adeiazoyn-ta-mikra-nisia-apokatoik/. (In Greek). Last access: 28/2/20

Strategic and Operational Program of Agios Efstratios Municipality, 2015-2019, 2015. 1st Phase: Strategic Planning, Agios Efstratios. Available at: http://www.agios-efstratios.gov.gr/files/stratigiko_dimou.pdf (In Greek). Last access 28/2/20

Tatsis, A., 2016. The Integrated Development of Agios Efstratios Island - The Historical Events of the 20th Century, Challenges and Prospects of Today. The Integrated Development of Mountainous and Geographically Isolated Areas. 8th Interdisciplinary Interuniversity Conference of NTUA and the MIRC NTUA, Metsovo: September 22-24. Available at: http://mirc.ntua.gr/foundation/8th_conference/ergasies/44_TATSHS_ATHANASIOS.pdf (In Greek). Last access 29/2/20

Terrainmaps, 2009. Hiking Map of Agios Efstratios (326), 1: 20,000, SKAI MAPS. (In Greek)

The Nations on Line Project, 2019. Political Map of Greece. Available at: https://www.nationsonline.org/oneworld/map/greece-politicalmap.htm. Last access 16/12/19

Tselepis, S., 2014. Design and Operational control of the Agios Efstratios Island Microgrid. 6th International Conference on Integration of Renewable and Distributed Energy Resources. Kyoto, Japan. Available at: http://www.cres.gr/kape/publications/photovol/new/S\%20\%20Tselepis\%20\%20\%20DESIGN\%20AND\%20OPERATIONAL\%20CONTROL\%200F\% 20THE\%20AGIOS\%20EFSTRATIOS\%20ISLAND\%20MICROGRID\%20\%20\%20_.pdf. Last access 29/2/20

Tselepis, S., Nikoletatos, I., 2014. Design and Operational control of the Agios Efstratios Island Microgrid. Technology and Science. International Journal of Distributed Energy Resources and Smart Grids, Vol 10, No 1, pages 57-77

Tsoukala, A., Spilanis, I., Banos-Gonzalez, I., Martinez-Fernandez, J., Esteve-Selma, M.A. \& Tsirtsis, G. (2018). An Exercise in Decision Support Modeling for Islands: Case Study for a Typical Mediterranean Island. Island Studies Journal, Vol. 13, No. 2, 2018, $185-202$. https://doi.org/10.24043/isj.62

Udo V.E. and Jansson P.M., 2009. Bringing the gaps for global sustainable development: A quantitative analysis. Journal of Environmental Management, Sep; 90 (12): 3700-7. https://doi.org/10.1016/j.jenvman.2008.12.020

Varnalis, K., 2014. Ai-Stratis, Exile Memories. Introduction-Editing-Comments Kakavanis H., Kastaniotis Publishing, Athens. (in Greek) WWF Greece, 2015. Blue development in the Mediterranean Sea. The Challenge of Good Environmental Status. Available at: http://www.medtrends.org/reports/MedTrends_GR-Report.pdf. (In Greek). Last access: 29/2/20

Zafirakis, D., Kavadias, K., Efthymiadis, S., Kapsali, M., Kaldellis, J., 2012. 100\% RES integration in the island of Agios Efstratios-Greece with the use of different wind-energy storage systems. European Wind Energy Conference and Exhibition 2012, EWEC 2012. 1. 1-10. 